\title{
Generation and Characterization of Monoclonal Antibodies to Recombinant Human Granulocyte-colony Stimulating Factor (G-CSF) and Its Muteins
}

\author{
Hajime Yoshida ${ }^{\dagger}$ and Sachiko Shitara ${ }^{\text {t+ }}$ \\ Kyowa Hakko Kogyo Co., Ltd., Tokyo Research Laboratories, \\ 3-6-6 Asahi-machi, Machida-shi, \\ Tokyo 194, Japan \\ Received November 16, 1988
}

\begin{abstract}
Monoclonal antibodies (MoAbs) reacting with human G-CSF and /or its muteins were established by cell fusion between P3.X63/Ag8.U1 myeloma cells and spleen cells from BALB/C mice immunized with recombinant human intact G-CSF or its mutein, designated ND28. Two MoAbs reacted with intact G-CSF and all kinds of muteins tested, designated KM341 and KM342, and two MoAbs specific for intact G-CSF, designated KM340 and KM343, were obtained from the mice immunized with recombinant human intact G-CSF.

The sera from the mice immunized with a mutein of G-CSF, ND28, reacted with intact G-CSF and all muteins tested. Two MoAbs specific for ND28, designated KM498 and KM511, were obtained from these mice. These MoAbs seem to recognize the sequence of a few amino acids that is peculiar for ND28. However, the epitopes recognized by KM498 and KM511 were maybe subtly different, because KM498 and KM511 could not completely inhibit each other.

Human G-CSF and/or its muteins could be measured by sandwich ELISA using these MoAbs with suitable combinations. The immuno-affinity column using KM342 or KM498 adsorbed G-CSFs or specifically ND28, previously. By elution with $0.15 \mathrm{M} \mathrm{NH}_{4} \mathrm{OH}$, the G-CSFs or ND28 were eluted with a high recovery.
\end{abstract}

G-CSF acts as a physiological granulopoietin, ${ }^{1,2)}$ and is expected to be used for granulocytopenic recovery from granulocytopenia caused by radiation and administration of anti-cancer drugs. Since the cloning and sequencing of the human G-CSF gene, ${ }^{3)}$ recombinant DNA technology has produced recombinant human $\mathrm{G}$-CSF ${ }^{1,4)}$ in sufficient amounts for clinical trials.

To find more effective G-CSF derivatives, many muteins of G-CSF were produced in Escherichia coli using recombinant DNA technology. One of them, designated ND-28, had two- to four-fold higher activity in vitro than intact G-CSF (personal communication).
For detection, quantification, and purification of G-CSF in industrial production and clinical studies, MoAbs specific for recombinant human G-CSF and/or ND-28, muteins of G-CSF were generated.

In this paper, we report the generation and characterization of the MoAbs against G-CSF and its muteins, and we describe their application to sandwich ELISA and to western blotting of G-CSF and its muteins.

\section{Materials and Methods}

G-CSF and its muteins. Recombinant intact human G$\mathrm{CSF}$, and its muteins, which have the amino acid se-

+ Present address: Kyowa Medex Co., Ltd., Fuji Laboratories, 1188 Shimotogari, Nagaizumi-cho, Sunto-gun, Shizuoka 411, Japan.

i† To whom reprint requests should be addressed.

Abbreviations: ELISA, enzyme linked immunosorbent assay; MoAb, monoclonal antibody; G-CSF, granulocytecolony stimulating factor; SDS, sodium dodecyl sulfate; PAGE, polyacrylamide gel electrophoresis; FCS, fetal calf serum; PBS, phosphate-buffered saline. 
Intact: Thr Pro Len Gly Pro Ala Ser Ser leu Pro Gin Ser Pho lon Lou lys Cys $\ldots$

\begin{abstract}
17 Ser:Thr Pro len gly Pro Ala Ser Ser Leu Pro Gln Sor the leu bu Lys Sor $\ldots$
1 Ser :Ser Pro len Gly fro Ala Ser Ser leu Pro Gin Ser Phe leu leu lys Cys $\cdots$

NC 59 :Thr Pro He Arg Ser Ala Ser Ser Lan Pro Ghi Ser Phe leu Len Lys Ser $\cdots$

ND 28 :Ala Pro Thr Tyr Ars Ala Ser Ser len Pro Gin Ser Phe Leu leu lys Ser $\ldots$

NCD 28:Ala Pro Thr Tyr Arg Mla Ser Ser leu Pro Gh Ser Phe Leu leu lys Cys $\cdots$

NC 95 : Ile: Pro Thr Arg Ser Ala Ser Ser Len Pro Gint Ser Phe Leu Len Lys Ser $\cdots$

NCC 95: lle Pro Thr Arg Ser Ala Sor Ser Leu Pro Gin Sor Phe leu len lts Cys $\cdots$

NC 93 :Asw Pro Gin Arg Ser Ala Ser Ser teu Pro Gin Sor Phe Leu leu L.ys Ser $\cdots$

NCC 93:Asn Pro Gln Arg. Ser Ala Ser Ser Leu Pro Glin Ser Phe len Lou lys Cys $\cdots$

Arg 4 :Thr Pro leu Arg Pro Na Ser Ser len Pro Giln Ser the Leu Len l,ys Cys $\cdots$

A1.45: Pro Ala Ser Sor len Pro Gin Ser Phe leu leu lys Ser $\cdots$

M-7 : $\quad$ Ser Leu fro Gin Sur Phe lou Len Iys Ser $\cdots$

M-2: Sor len Pro Cln Ser the leu leu lys Cys $\cdots$
\end{abstract}

Fig. 1. Sequence of Seventeen N-Terminal Amino Acids of Human Intact G-CSF and Its Muteins.

quences shown in Fig. 1, were produced and purified in our laboratories.

Immunization and fusion. Eight-week-old female $\mathrm{BALB} / \mathrm{c}$ mice were immunized by $i . p$. injection of $100 \mu \mathrm{g}$ of the purified G-CSF or ND-28, a mutein of G-CSF, with $2 \mathrm{mg}$ of aluminum gel and $10^{9}$ cells of Bordetella pertusis as adjuvant, per head. Three or four consecutive injections of the same amount of the immunogen without adjuvant were given i.p. to the same mice at weekly intervals starting 2 weeks after the first immunization. The mice were killed 3 or 4 days after the last injection. The spleen cells were fused with P3.X 63/Ag8. U1 (P3U1), at a 5:1 ratio of spleen cells to P3U1, in PEG-1000 by a modification of the method of Köhler and Milstein. ${ }^{5)}$ The fused cells were distributed in $100 \mu \mathrm{l}$ samples into 96-well culture plates (Becton Dickinson Labware, Oxnard, U.S.A.) at a concentration of $10^{5}$ spleen cells per well. The growth medium used consisted of RPMI 1640 (Nissui, Tokyo, Japan) containing $10 \%$ fetal calf serum. After three consecutive changes of the culture supernatant with a growth medium containing $1 \times 10^{-4} \mathrm{M}$ hypoxanthine, $4 \times 10^{-7} \mathrm{M}$ aminopterin, and $1.6 \times 10^{-5} \mathrm{M}$ thymidine, the antibody titer to G-CSF or ND-28 in the culture supernatant was measured by binding ELISA. Positive wells were subcloned twice by a limiting dilution method (one cell per three wells).

Binding ELISA. G-CSF or its mutein was distributed at
$10 \mu \mathrm{g}$ per well into 96-well microtiter plates (Flow Labs. Inc., McLean, U.S.A.). After incubation at $4^{\circ} \mathrm{C}$ overnight or at $37^{\circ} \mathrm{C}$ for $2 \mathrm{hr}$, unbound materials were removed and $200 \mu \mathrm{l}$ of phosphate-buffered saline containing $1 \%(\mathrm{w} / \mathrm{v})$ bovine serum albumin (BSA-PBS) was added to each well. The wells were washed three times with PBS after incubation under the conditions described above. One hundred microliters of MoAb or of the culture supernatant of a hybridoma clone was added to each well. The wells, which were incubated under the same conditions as above, were washed three times with PBS containing $0.05 \%$ Tween 20 (Tween-PBS). One hundred microliters of horseradish peroxidase (HRP)-conjugated rabbit anti-mouse immunoglobulin (Dakopatts, Glostrup, Denmark) was then added to each well and the plates were incubated at $37^{\circ} \mathrm{C}$ for $2 \mathrm{hr}$. After washing five times with Tween-PBS, $100 \mu \mathrm{l}$ of peroxidase substrate solution [containing $0.05 \%$ 2,2'-azino-di-(3-ethylbenzothiazoline) sulfonic acid diammonium salt (ABTS; Nakarai, Kyoto, Japan), and $0.1 \%$ hydrogen peroxide in $0.1 \mathrm{M}$ sodium citrate, $\mathrm{pH} 4.2$ ] was added. After $1 \mathrm{~min}$ at room temperature, the reaction was stopped by the addition of $100 \mu \mathrm{l}$ of $5 \%$ SDS. The absorbance of each well was measured by micrititer plate analyzer (Japan Intermed, NJ-2000, Tokyo, Japan) at $415 \mathrm{~nm}$ using $490 \mathrm{~nm}$ as reference.

Preparation of MoAbs. The established hybridomas were propagated as ascites in Pristane (Aldrich Chemical 
Co., Inc., Milwaukee, U.S.A.)-treated nude mice (BALB/c $\mathrm{nu} / \mathrm{nu})$.

A large amount of purified MoAbs were obtained from the ascites by ammonium sulfate precipitation, ionexchange chromatography with DEAE-cellulose, DE-52 (Whatman, Clifton, U.S.A.), and affinity chromatography using an Affi-Gel Protein MAPS-II kit (Bio-Rad Laboratories, Richmond, U.S.A.). Part of the purified MoAbs were biotinylated by the method of Guesdon et al. ${ }^{67}$ Briefly, purified MoAb was dialyzed against $0.1 \mathrm{M}$ $\mathrm{NaHCO}_{3}$ (pH 8.0) containing $0.5 \mathrm{M} \mathrm{NaCl}$ overnight at $4^{\circ} \mathrm{C}$. One milliliter of dialyzed $\mathrm{MoAb}(1 \mathrm{mg} / \mathrm{ml})$ was mixed with $100 \mu \mathrm{l}$ of $N$-hydroxysuccinimidobiotin (Sigma, St. Louis, U.S.A.) dissolved in $N, N^{\prime}$-dimethyl formamide $(1 \mathrm{mg} / \mathrm{ml})$. The mixture was incubated for $4 \mathrm{hr}$ at room temperature, and then was extensively dialyzed against $10 \mathrm{~mm}$ phosphate buffer (pH 7.2) containing $0.5 \mathrm{M} \mathrm{NaCl}$.

Quantification of G-CSF and its muteins (Sandwich ELISA). For sandwich ELISA, wells of a 96-well EIA plate (Flow Laboratories, Inc., McLean, U.S.A.) were coated with $50 \mu \mathrm{l}$ of purified $\mathrm{MoAb}(10 \mu \mathrm{g} / \mathrm{ml})$ at $4^{\circ} \mathrm{C}$ overnight. After removal of the antibody solution, residual protein-binding sites on the plates were blocked with $100 \mu \mathrm{l}$ of $1 \%$ BSA-PBS. Then $50 \mu \mathrm{l}$ of samples containing $\mathrm{G}-\mathrm{CSF}$ or its muteins at various concentrations were added to the wells and incubated overnight at $4^{\circ} \mathrm{C}$. After these were washed with Tween-PBS, $50 \mu$ l of avidinbiotin-peroxidase complex (ABC Kit; Vector, Burlingame, U.S.A.) was added and incubated at room temperature for $1 \mathrm{hr}$. Then the wells were washed with Tween-PBS and $50 \mu 1$ of ABTS solution was applied for $2 \mathrm{~min}$ at room temperature. The absorbance at $415 \mathrm{~nm}$ was measured.

SDS-PAGE and western blotting. SDS-PAGE was done in $10 \%(\mathrm{w} / \mathrm{v})$ polyacrylamide gel by the method of Laemmli." Two micrograms of G-CSF and its muteins were developed by SDS-PAGE, and they were transferred to nitrocellulose membranes in transfer buffer $(0.025 \mathrm{M}$ Tris, $0.2 \mathrm{~m}$ Glycine, $20 \% \mathrm{MetOH}, \mathrm{pH} 8.3$ ) overnight at $4{ }^{\circ} \mathrm{C}$ by the method of Towbin et al ${ }^{8)}$ The dried nitrocellulose membrane was soaked in $3 \%$ gelatin solution to block the remaining protein-binding sites. Then it was dipped in culture supernatant of a hybridoma or in a solution of $\mathrm{MoAb}$ and incubated at room temperature for $2 \mathrm{hr}$. After being washed 3 times with Tween-PBS, peroxidase-labeled antimouse immunoglobulin was left to react at room temperature for $2 \mathrm{hr}$. After it was washed 3 times, the membrane was developed with $0.06 \%$ HRP Color Development Reagent (Bio-Rad) in $0.02 \mathrm{M}$ Tris $/ 0.5 \mathrm{M}$ $\mathrm{NaCl}, \mathrm{pH} 7.5$. The reaction was stopped by soaking the membrane in cold water. Another membrane was stained with amido black after transfer.

Immuno-affinity chromatography. Purified $\mathrm{MoAb}$ was dialyzed against the coupling buffer $(0.1 \mathrm{M} \mathrm{NaHCO}, 0.5 \mathrm{M}$
$\mathrm{NaCl}, \mathrm{pH} 8.0$ ) overnight at $4^{\circ} \mathrm{C}$. Four milliliters of tresylactivated Sepharose 4B gel (Pharmacia Fine Chemical, Uppsala, Sweden) washed and buffered with the coupling buffer was added to dialyzed antibody solutions and was mixed for $2 \mathrm{hr}$ at room temperature. After this was washed with phosphate buffer containing $0.5 \mathrm{M} \mathrm{NaCl}$, one-half milliliter of gel was poured into the column and equilibrated at $4^{\circ} \mathrm{C}$ with phosphate buffer containing $0.5 \mathrm{M} \mathrm{NaCl}$.

Two hundred micrograms of partially purified $\mathrm{MoAb}$ were put onto the thus-prepared immonoaffinity column. After washing the column with phosphate buffer containing $0.5 \mathrm{M} \mathrm{NaCl}$, adsorbed components were eluted with $0.15 \mathrm{M} \mathrm{NH}_{4} \mathrm{OH}$. Protein in each $1-\mathrm{ml}$ fraction was measured by the method of Lowry et al., ${ }^{9)}$ and G-CSF or ND28 contents by the sandwich ELISA described above. Before ELISA, the eluted fractions were dialyzed against phosphate buffer containing $0.5 \mathrm{M} \mathrm{NaCl}$.

\section{Results}

Generation of MoAbs against $G-C S F$ or $N D-28$

Two 8-week-old female BALB/c mice were immunized by recombinant human intact $G$ CSF and five mice were immunized by ND-28, a mutein of G-CSF. The sera from all mice reacted with both intact G-CSF and ND-28, but not to bovine serum albumin (BSA) and pKYP-10 (admixed proteins from host Escherichia coli). (Data not shown.)

Finally, four MoAbs, designated KM340, KM341, KM342, and KM343 from the mice immunized intact G-CSF, and two MoAbs, designated KM498 and KM511, from the mice immunized with ND28 were selected for their reactivity to $\mathrm{G}-\mathrm{CSF}$ and/or its muteins. The isotypes of these MoAbs were identified by the double diffusion method. All MoAbs were $\mathrm{IgG}_{1}$.

\section{Binding specificities of $M O A b s$}

The reactivities by ELISA of KM340, KM341, KM342, and KM343 to various recombinant human proteins are shown in Fig. 2. KM342 reacted weakly with $r$-huinterferon- $\gamma($ IFN- $\gamma)$ and $r$-hu-interferon- $\beta$ (IFN- $\beta$ ). KM340, KM341, and KM343 reacted only to $\mathrm{r}-\mathrm{hu}-\mathrm{G}-\mathrm{CSF}$. This specificity of these MoAbs to r-hu-G-CSF was confirmed by western blotting (Fig. 3).

Table I shows the specificities of MoAbs which were examined by binding ELISA using 
various muteins of G-CSF. KM341 and KM342 reacted with intact G-CSF and all muteins of G-CSF tested. KM340 and KM343

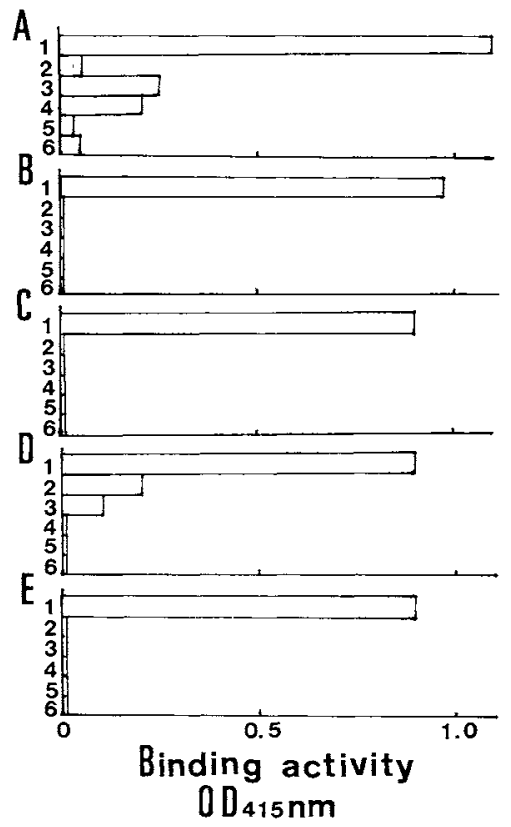

Fig. 2. Reactivity of MoAbs Derived from the Mice Immunized with Recombinant G-CSF to Various $\mathrm{Re}$ combinant Proteins in Binding ELISA.

A), anti-human G-CSF mouse serum; B), KM340; C), KM341; D), KM342; and E), KM343.

Antigens: 1, intact G-CSF; 2, human interferon- $\gamma ; 3$, human interferon- $\beta ; 4$, human interleukin-1; 5 , human interleukin-2; 6 , admixture of proteins prepared from host Escherichia coli. reacted with intact, 17-Ser, 1-Ser, and Arg4. KM498 and KM511 reacted with only ND28 and NCD28.

In western blotting, KM498 gave only the band of ND28 (Fig. 4).

These results suggested that KM340 and KM343, KM341, and KM342, and KM498 and KM511 recognized the $\mathrm{N}$-terminal several amino acid sequence of intact hu-G-CSF, the C-terminal amino acid sequence behind the 7 th position of intact hu-G-CSF, and the Nterminal several amino acid sequence of ND28, respectively. As shown in Fig. 5, KM498 and KM511 did not completely inhibit the binding to ND28 of each other. It seems that the epitopes of KM498 and KM511 are different.

\section{Quantification of G-CSFS by sandwich-type ELISA}

Quantification of intact G-CSF and/or ND28 by sandwich-type ELISA were examined. The titration curve of intact G-CSF by sandwich-type ELISA using KM340 and biotinylated KM341 is shown in Fig. 6. It was demonstrated that in the range of $2.5 \sim 80 \mathrm{ng} / \mathrm{ml}$ intact G-CSF could be quantified by this assay system. ND28 was not identified in this sandwich-type ELISA.

Figure 7 shows a titration curve of intact GCSF and ND28 by sandwich-type ELISA
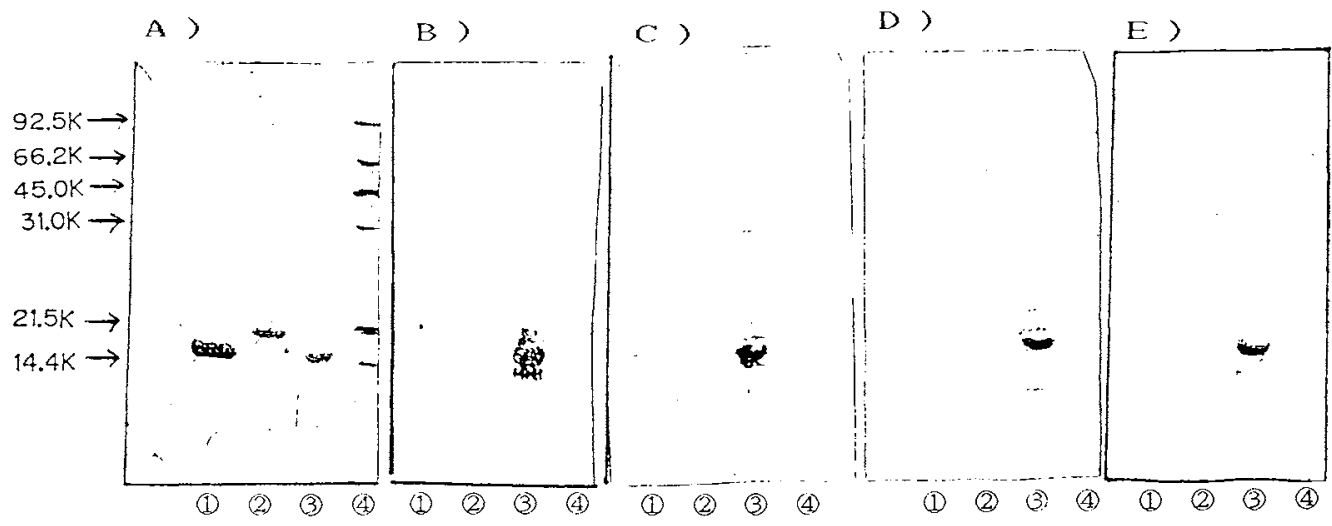

Fig. 3. Specificity of Anti-G-CSF MoAbs in Western Blotting.

1 , human interferon- $\gamma ; 2$, human interferon- $\beta$; 3 , intact G-CSF; 4 , MW markers were developed by SDSPAGE and transferred to nitrocellulose membranes. After transfer, one membrane was stained with amido black, A), and the others were stained with KM340, B), KM341, C), KM342, D) and KM343, E). 
Table I. Reactivity of Anti-G-CSFs MoAbs to Intact G-CSF and Its Muteins

\begin{tabular}{lcccccc}
\hline & \multicolumn{7}{c}{ Monoclonal antibody } \\
\cline { 2 - 5 } Antigen & KM340 & KM341 & KM342 & KM343 & KM498 & KM511 \\
\hline Intact & 0 & 0 & 0 & 0 & $\times$ & $\times$ \\
17 Ser & 0 & 0 & 0 & 0 & ND & ND \\
1 Ser & 0 & 0 & 0 & 0 & $\times$ & $\times$ \\
NC 59 & $\times$ & 0 & 0 & $\times$ & $\times$ & $\times$ \\
ND 28 & $\times$ & 0 & 0 & $\times$ & 0 & 0 \\
NCD 28 & $\times$ & 0 & 0 & $\times$ & 0 & 0 \\
NC 95 & $\times$ & 0 & 0 & $\times$ & ND & ND \\
NCC 95 & $\times$ & 0 & 0 & $\times$ & ND & ND \\
NC 93 & $\times$ & 0 & 0 & $\times$ & $\times$ & $\times$ \\
NCC 93 & $\times$ & 0 & 0 & $\times$ & ND & ND \\
Arg 4 & $O$ & 0 & 0 & 0 & ND & ND \\
41 4S & ND & ND & ND & ND & $\times$ & $\times$ \\
M-7 & ND & ND & ND & ND & $\times$ & $\times$ \\
M-7-2 & $\times$ & 0 & 0 & $\times$ & ND & ND \\
\hline
\end{tabular}

Reaction: $O$, positive; $\times$, negative.

ND, not done.

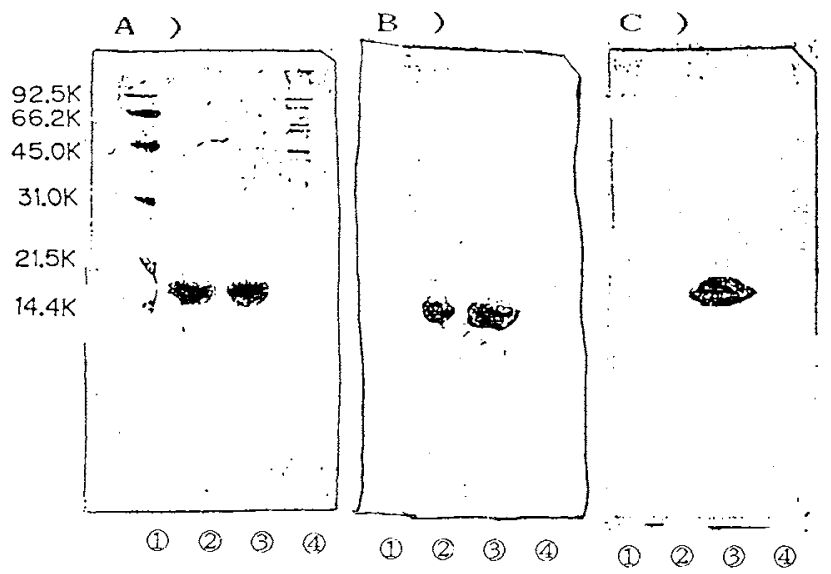

Fig. 4. Specificity of KM498 in Western Blotting.

(1), MW markers; (2), intact G-CSF; (3), ND28; (4), admixture of proteins prepared from host $E$. coli, were developed. by SDS-PAGE and transferred to nitrocellulose membranes.

After transfer, one was stained with amido black, A), and others were stained with anti-ND28 mouse serum,

B) and KM498, a anti-ND28 MoAb, C), respectively.

using KM341 and biotinylated rabbit anti-GCSF polyclonal antibody. This assay system allows measurement of intact G-CSF and ND28 of concentrations from 2 to $10 \mathrm{ng} / \mathrm{ml}$.

The value of $\mathrm{OD}_{415}$ of sandwich-type ELISA using KM498 and biotinylated KM341 corresponded well to the concentrations of ND28 between $0.05 \sim 10 \mu \mathrm{g} / \mathrm{ml}$ (Fig. 8 ).

In this system intact G-CSF was not iden- tified.

Purifications of G-CSFs by affinity chromatography

Intact G-CSF solution $(62.7 \mu \mathrm{g} / \mathrm{ml})$ was put on the KM342 coupled Sepharose 4B column which was prepared as described in Materials and Methods.

Unbound materials having no antigenic ac- 


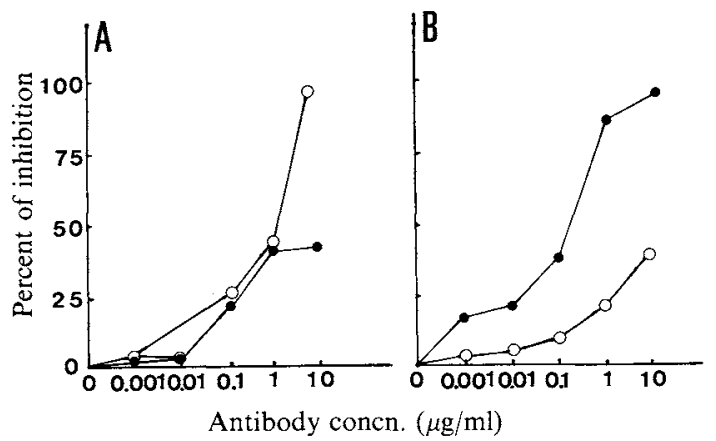

Fig. 5. Inhibition of Binding Activity to ND28 of Biotinylated KM498 and Biotinylated KM511 by KM511 and KM498.

Fifty $\mu \mathrm{l}$ of the mixture of the biotinylated MoAbs (A, biotinylated KM498; B, biotinylated KM511) at the concentration of $20 \mu \mathrm{g} / \mathrm{ml}$ and various concentrations of native MoAb (inhibitors: $O$, KM498;, KM511) were added to each well of a 96-well EIA plate which was coated beforehand with ND28 and incubated at room temperature for $2 \mathrm{hr}$. After washing with $0.05 \%$ Tween 20 in PBS, $50 \mu \mathrm{l}$ of avidin-peroxidase $(2.5 \mu \mathrm{g} / \mathrm{ml})$ were added at room temperature for $1 \mathrm{hr}$. Enzyme activity was measured as described in Materials and Methods using ABTS as a substrate.

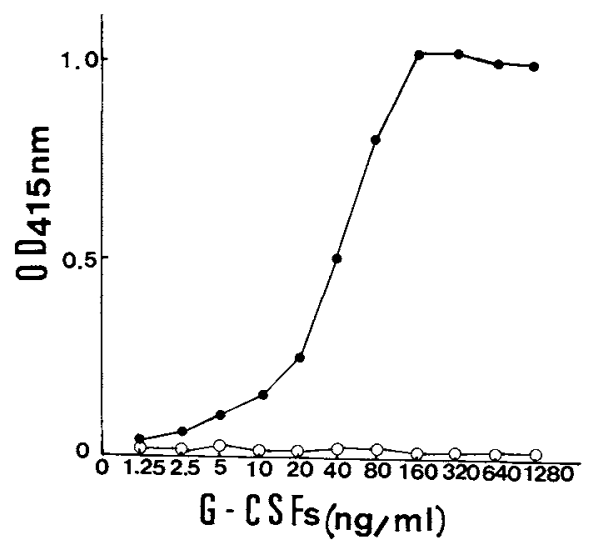

Fig. 6. Titration Curve of Intact G-CSF by Sandwich ELISA Using KM340 and Biotinylated KM341.

Various concentrations of intact G-CSF (O), and ND28, a mutein of G-CSF $(O)$. were measured by sandwich ELISA using KM340 and biotinylated KM341.

tivity effused in the first several fractions. After washing, G-CSF was eluted as a single peak with $0.15 \mathrm{M} \mathrm{NH}_{4} \mathrm{OH}$. This eluted G-CSF was a single protein containing impurities by SDSPAGE (data not shown). In the purification

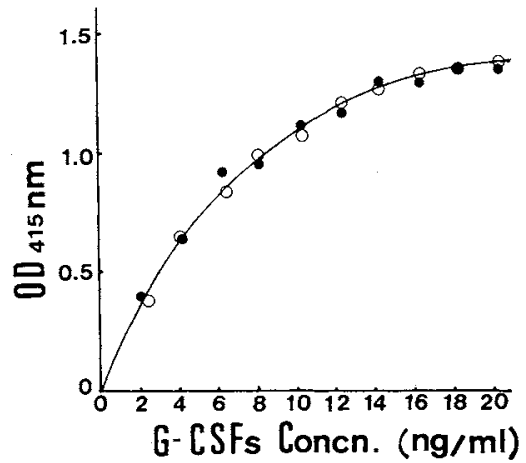

Fig. 7. Titration Curve of Intact G-CSF and ND28 by Sandwich ELISA Using KM341 and Biotinylated Rabbit Anti-G-CSF Polyclonal Antibody.

Various concentrations of intact G-CSF (O), and ND28 $(O)$ were measured by sandwich ELISA using KM341 and biotinylated rabbit anti-G-CSF polyclonal antibody.

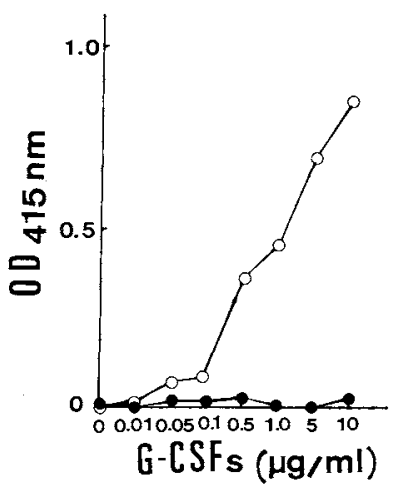

Fig. 8. Titration Curve of ND28 by Sandwich ELISA Using KM498 and Biotinylated KM341.

Various concentrations of intact G-CSF (O), and ND28 (O) were measured by sandwich ELISA using KM498 and biotinylated KM341.

of G-CSF, affinity chromatography using KM342 is considered to be superior to the conventional method which needs many steps and has a low yield.

By the affinity chromatography using KM498, a MoAb specific to ND28, the efficient purification of ND28 similarly was performed.

\section{Discussion}

Several MoAbs were established from the 
mice immunized with human G-CSF and its mutein produced by recombinant DNA technology. Two MoAbs, KM341 and KM342, derived from the mice immunized with intact G-CSF reacted with intact G-CSF and all kinds of its muteins tested. These MoAbs seem to recognize the epitope in the C-terminal behind position 7. The other two MoAbs derived from mice immunized with intact GCSF, KM340 and KM343, reacted with only intact G-CSF, 1-Ser, and 17-Ser. The epitope is a sequence of several amino acids between positions 2 to 6 of intact G-CSF. The antisera prepared from the mice immunized with ND28, a mutein of human G-CSF, reacted with intact G-CSF and all of the muteins tested. Two MoAbs derived from the mice, KM498 and KM511, reacted specifically with only ND28 and NCD28. KM498 and KM511 seem to recognize the sequence including a few amino acids peculiar to ND28 and NCD28. The epitopes of KM498 and KM511 may not be quite the same, because KM498 and KM511 were not able to completely inhibit each other.

These anti-human G-CSFs MoAbs are useful for detection, quantification (monitoring), and purification of G-CSF and/or its muteins.
Further studies are in progress to test the relation of the epitopes and the G-CSF activity using these anti-G-CSFs MoAbs.

Acknowledgment. The authors are grateful to Dr. S. Itoh and Dr. Y. Yokoo in our laboratories for providing antigens and helpful advice.

\section{References}

1) M. Fujisawa, Y. Kobayashi, T. Okabe, F. Takaku, Y. Komatsu, and S. Itoh, Jpn. J. Cancer Res. $(G A N N), 77,866$ (1986).

2) M. Shimamura, Y. Kobayashi, A. Yuo, A. Urabe. T. Okabe, Y. Komatsu, S. Itoh and F. Takaku, Blood, 69, 353 (1987)

3) S. Nagata, M. Tsuchiya, S. Asano, Y. Kaziro, T. Yamazaki, O. Yamamoto, Y. Hirata, N. Kubota, M. Oheda, H. Nomura and M. Ono, Nature, 319, 415 (1986).

4) L. M. Souza, T. C. Boone, J. Gabriove, K. M. Zsebo, D. C. Murrodock, J. Bruszewski, K. K. Chen, M. A. S. Moore, R. Mertelsmann and K. Welte, Science, 232, 61 (1986).

5) G. Köhler and C. Milstein, Nature, 256, 495 (1975).

6) J. L. Gueston, T. Ternynck and S. Arramas, $J$. Histochem. Cytochem., 27, 1131 (1979).

7) U. K. Laemmli, Nature, 227, 680 (1970).

8) H. N. Towbin, T. Stachelin, and J. Gorden, Proc. Natl. Acad. Sci., U.S.A., 76, 4350 (1979).

9) O. H. Lowry, N. J. Rosebrough, A. L. Farr and R. J. Randall, J. Biol. Chem., 193, 265 (1951). 